6

\title{
A study on the entrainment and mixing process in the continental stratocumulus clouds measured during the RACORO campaign
}

Corresponding Author:

24 Prof. Seong Soo Yum

25 Department of Atmospheric Sciences, Yonsei University, Seoul 03722, Korea

\section{ssyum@yonsei.ac.kr}
${ }^{3}$ CMA Key Laboratory for Aerosol-Cloud-Precipitation, Key Laboratory of Meteorological Disaster of Ministry of Education, Nanjing University of Information Science and Technology (NUIST), Nanjing, Jiangsu, China




\section{Abstract}

31 Entrainment and mixing processes and their effects on cloud microphysics in the continental stratocumulus clouds observed in Oklahoma during the RACORO campaign are analyzed in the frame of homogeneous and inhomogeneous mixing concepts by combining the approaches of microphysical correlation, mixing diagram, and transition scale (number). A total of 110 horizontally penetrated cloud segments is analyzed. Mixing diagram and cloud microphysical relationship analyses show homogeneous mixing trait of positive relationship between liquid water content (L) and mean volume of droplets (V) (i.e., smaller droplets in more diluted parcel) in most cloud segments. Relatively small temperature and humidity differences between the entraining air from above the cloud top and cloudy air and relatively large turbulent dissipation rate are found to be responsible for this finding. The related scale parameters (i.e., transition length and transition scale number) are relatively large, which also indicates high likelihood of homogeneous mixing. Clear positive relationship between L and vertical velocity (W) for some cloud segments is suggested to be evidence of vertical circulation mixing, which may further enhance the positive relationship between L and V created by homogeneous mixing.

Keywords: 


\section{Introduction}

In warm clouds, growth of cloud droplets occurs largely via two processes, condensation and collision-coalescence. It is observed that precipitation in warm clouds can be initiated within 30 minutes after cloud formation (Rogers and Yau, 1989). However, according to adiabatic condensational growth theory, too much time is required for cloud droplets to grow large enough to initiate the collision-coalescence process and moreover cloud droplet spectrum becomes narrowed as cloud droplets grow, hampering realistically fast growth of cloud droplets to raindrops. In contrast, observed cloud droplet spectra from aircraft measurements were not narrowed or even became wider with the cloud altitude (Hudson and Yum, 1997; Yum and Hudson, 2001, 2005). These observations indicate that in real clouds, the collision-coalescence process can be much more efficient than is predicted from adiabatic calculation of condensational droplet growth.

Many studies have tried to explain this conspicuous difference between observation and theory in the past few decades (Beard and Ochs, 1993; Liu and Hallett, 1998; Liu et al., 2002; Devenish et al., 2012; Grabowski and Wang, 2013). The entrainment and mixing of clear and cloudy air has been suggested as a process responsible for the discrepancy. Two mixing mechanisms have been proposed: homogeneous and inhomogeneous mixing (e.g., Warner, 1973; Baker et al., 1980) and evidence for either of the two mixing mechanisms have been reported (Paluch, 1979; Pawlowska et al., 2000; Burnet and Brenguier, 2007; Haman et al., 2007; Gerber et al., 2008; Lehmann et al., 2009; Lu et al., 2011; Beals et al., 2015; Yang et al., 2016). Notably, Burnet and Brenguier (2007) showed that the Damköhler number, defined as 
scale $\left(\tau_{\mathrm{e}}\right)$ could be used as a parameter that indicates which mixing mechanism is dominant. Lehmann et al. (2009) argued that the mixing mechanism could be better determined with the transition length scale instead of the Damköhler number because of the uncertainty in knowing the turbulent mixing length scale. The results varied by cloud region; homogeneous mixing (HM) appeared more frequently in the vicinity of the cloud core, while inhomogeneous mixing (IM) appeared more frequently in more diluted cloud regions (Lehmann et al., 2009). Similarly, Lu et al. (2011) proposed that the transition scale number defined as the ratio of transition length to the Kolmogorov length scale could be used as a parameter to estimate mixing mechanisms; a higher transition scale number corresponds to a greater tendency of homogeneous mixing.

Recently Yum et al. (2015) speculated from the analyses of observed marine stratocumulus clouds over the South East Pacific that cloud parcels diluted by entrained air from above the cloud top would be negatively buoyant than the adjacent undiluted cloud parcels and therefore could induce vertical circulation. Although the mixing of the entrained air near the cloud top might have been inhomogeneous as the scale parameters suggested for these marine stratocumulus clouds, the cloud microphysical relationships changed to indicate homogeneous mixing due to vertical circulation. An important point is that the inhomogeneous mixing process could promote warm rain initiation. However, there are few indications of such effect in many observational studies. Thus, detailed and thorough analyses are needed to enhance our understanding on this issue.

Stratocumulus clouds are sensitive to aerosol properties, which make significant differences in the cloud microphysical and radiative properties (Andrejczuk et al., 2014; Lábó et al., 2016). Compared to maritime stratocumulus clouds, continental stratocumulus clouds 
develop under different thermodynamic and aerosol conditions. Despite their importance continental stratocumulus clouds have been relatively under-investigated. In this study, we examine the entrainment and mixing mechanisms and their effects on cloud microphysics for continental stratocumulus clouds. Similarly to Yum et al. (2015), mixing diagram analysis is made to examine what type of mixing mechanism appears dominantly in continental stratocumulus clouds. Also examined are the scale parameters mentioned above to see if they could serve as an adequate measure to estimate the mixing mechanism. Lastly, the results are compared with those for marine stratocumulus clouds to identify the effects of different thermodynamic conditions on the entrainment and mixing process.

\section{Data}

The data used in this study were obtained from the Routine AAF CLOWD Optical Radiative Observations (RACORO) campaign administered by the ARM Aerial Facility (AAF) at the Southern Great Plains (SGP) ARM Climate Research Facility during the fivemonth period from January 22 to June 302009 (Vogelmann et al., 2012). For cloud measurements, the Center for Interdisciplinary Remotely-Piloted Aircraft Studies (CIRPAS) Twin Otter aircraft was used. Continental boundary layer clouds were frequently observed over the SGP site during the measurement period. Data for this study were collected from the flights on February 6, 8, 26, April 19, and May 6, when stratocumulus cloud was the main cloud type. The flight tracks on all of these days were confined to a narrow region. Particularly, the data from April 19 reveals that the aircraft track was identically triangular at several different horizontal altitudes during this flight. 

(CAS) manufactured by Droplet Measurement Technologies (DMT); it has a resolution of 10 $\mathrm{Hz}$, corresponding to a spatial resolution of $5 \mathrm{~m}$ (the mean speed of the Twin Otter aircraft was $50 \mathrm{~m} \mathrm{~s}^{-1}$ ). While CAS can observe diameters from $0.58 \mu \mathrm{m}$ to $50.1 \mu \mathrm{m}$ with 20 bins, the data between bin number $10(1.78 \mu \mathrm{m}$ diameter $)$ and $20(50.1 \mu \mathrm{m}$ diameter $)$ were utilized in this study to consider only the cloud droplets. The cloud microphysical properties, such as liquid water content $(\mathrm{L})$, cloud droplet number concentration $(\mathrm{N})$, and mean volume $(\mathrm{V})$, were calculated using these spectral data from CAS. A Cloud Imaging Probe (CIP), which can measure particles within the $15 \sim 1562 \mu \mathrm{m}$ diameter range, was used to detect drizzle drops. The drizzle liquid water content $\left(\mathrm{L}_{\mathrm{d}}\right)$ also is calculated by integrating CIP size distribution except the bin 1 and 2 which are overlapped with CAS; if $L_{d}$ is larger than 0.005 $\mathrm{g} \mathrm{m}^{-3}$, these drizzling clouds were excluded from the analysis to avoid the impact of the collision-coalescence process on cloud microphysics (Lu et al., 2014). Temperature (T) and dew point temperature $\left(\mathrm{T}_{\mathrm{d}}\right)$ were measured with a Rosemount probe and a Diode Laser Hygrometer (Diskin et al., 2002; Podolske et al., 2003), respectively. Vertical velocity (W) was measured with a five-hole gust probe.

Classification of the cloudy segment is very important. Here, we apply the criteria of L > $0.001 \mathrm{~g} \mathrm{~m}^{-3}$ and $\mathrm{N}>10 \mathrm{~cm}^{-3}$ (Deng et al., 2009; Lu et al., 2014). When both thresholds are satisfied for more than 10 consecutive seconds, such data segment is classified as an adequate cloud segment. In all, 110 cloud segments were found, and the data length ranged from approximately $500 \mathrm{~m}$ to $21 \mathrm{~km}$, assuming an aircraft speed of $50 \mathrm{~m} \mathrm{~s}^{-1}$. The average $\mathrm{N}$ in each segment ranged from 300 to $400 \mathrm{~cm}^{-3}$. Both $\mathrm{N}$ and $\mathrm{V}$ usually decrease at cloud side edges, which would falsely indicate a trait of homogeneous mixing. Therefore, severely diluted 
144 regions $\left(\mathrm{N}<100 \mathrm{~cm}^{-3}\right)$ near cloud side edges were discarded from the analysis to remove the cloud edge effect and focus on the modulation of cloud microphysical relationships due to entrainment and mixing of the clear air from above cloud top. The turbulent dissipation rate $(\varepsilon)$ is calculated from the true air speed $(\mathrm{U})$ measured at $10 \mathrm{~Hz}$ using the following structure function approach (Poellot and Grainger, 1991) as,

$$
\varepsilon=\left(\frac{\mathrm{D}}{\mathrm{C}}\right)^{\frac{3}{2}} \frac{1}{\delta \mathrm{x}}, \text { where } \mathrm{D}=(\mathrm{U}(\mathrm{x})-\mathrm{U}(\mathrm{x}+\delta \mathrm{x}))^{2}
$$

In the above formula, $\mathrm{C}=1.77$ is the Kolmogorov constant and the $\delta \mathrm{x}$ is the interval length between data samples at $0.5 \mathrm{~s}$ interval, which is about $25 \mathrm{~m}$. D is the structure function that is applicable when turbulence is isotropic. The interval length between data samples is within the inertial sub-range. To note is that $U$ in the above expression is computed by using a moving average of 9 samples ( $0.9 \mathrm{~s}$ data length) to minimize data noise.

Figure 1a shows the time variations of flight altitude, cloud microphysical variables, and $\varepsilon$ during the April 19 flight. Photographs taken during the flight (not shown here) indicate that it was overcast on this day. A, B and C in Fig. 1a are the main cloud regions analyzed in this study, where altitude was raised slightly in step from A to C. The region A represents the middle level of clouds, while $\mathrm{B}$ and $\mathrm{C}$ are closer to the cloud top. $\mathrm{L}$ tends to become large from $\mathrm{A}$ to $\mathrm{C}$, and generally $\mathrm{N}$ correlates well with $\mathrm{L}$. The turbulent dissipation rate $\varepsilon$ is low in the non-cloudy region but become clearly larger with stronger fluctuation in the cloudy region (most from 10 to $100 \mathrm{~cm}^{2} \mathrm{~s}^{-3}$ ), due to turbulence generated by condensational heating and evaporative cooling inside clouds. Flight tracks were narrowly spaced in a repeated fashion as demonstrated in Fig. 1b. The triangular flight patterns was repeated in the three horizontal legs, A, B and C. Figure 1c shows the vertical variation of $\mathrm{L}, \mathrm{T}$ and $\mathrm{T}_{\mathrm{d}}$, but it is 
difficult to determine the cloud base altitude because the aircraft did not fly below the middle altitude of clouds.

It was found that the measured temperature was systematically colder by $1 \sim 2{ }^{\circ} \mathrm{C}$ inside the clouds than outside during horizontal aircraft tracks. Unfortunately, the reverse flow setup, which is usually applied for aircraft temperature measurement to reduce the bias caused by evaporative cooling due to sensor wetting (Wang and Geerts, 2009), was not applied for the temperature measurement in this campaign. Therefore, the temperature sensor element was subject to direct wetting in the cloudy air stream and suffered from severe evaporative cooing as reported also in Heymsfield et al. (1979). Due to this problem, the measured $\mathrm{T}$ was $\sim 1{ }^{\circ} \mathrm{C}$ lower than $T_{d}$ inside the clouds. This much difference between the two is unexpectedly large for stratocumulus clouds where supersaturation is generally very small. More importantly, temperature underestimation inside the clouds limits our ability to assess the change of thermodynamic properties caused by entrainment and mixing. with a depth of $\sim 50 \mathrm{~m}$. $\mathrm{T}$ was higher and $\mathrm{T}_{\mathrm{d}}$ was lower above the EIL than inside the clouds. clouds, compared to that for marine ones.

\section{Mixing diagram and Correlation coefficients}


There are basically two mixing mechanisms proposed in the literature. One is that the entrained air and the cloudy air are mixed evenly and all cloud droplets evaporate with the same proportion (Warner, 1973). This type of mixing is referred to as homogeneous mixing. The other type of mixing is inhomogeneous mixing, where the entrained air mixes with only some portion of cloud parcel and evaporate all droplets in this portion completely while the droplets in the rest of the cloud parcel remain intact (Baker et al., 1980). Expected relationships between cloud microphysical parameters for different mixing scenarios are suggested in Yum et al. (2015). Following the same categorization, all cloud segments are classified in Table 1. Basically two patterns emerge dominantly for the 110 cloud segments. In 93 segments, the linear correlation coefficients between $\mathrm{N}$ and $\mathrm{V}, \mathrm{N}$ and $\mathrm{L}$, and $\mathrm{V}$ and $\mathrm{L}$ $\left(\Gamma_{\mathrm{N}-\mathrm{V}}, \Gamma_{\mathrm{N}-\mathrm{L}}\right.$, and $\left.\Gamma_{\mathrm{V}-\mathrm{L}}\right)$ are all positive, which is consistent with the data scatter pattern for the clouds subject to homogeneous mixing. If mixing was inhomogeneous, $\mathrm{L}$ and $\mathrm{N}$ of the cloud parcel diluted by the entrained air would decrease, but the mean volume of the droplets would not change. If so, $\Gamma_{\mathrm{N}-\mathrm{L}}$ would still be positive but $\Gamma_{\mathrm{N}-\mathrm{V}}$ and $\Gamma_{\mathrm{V}-\mathrm{L}}$ should be practically zero. However, there is no segment that shows such correlations. Lastly, in 13 segments L varies relatively little in each cloud segment and $\Gamma_{\mathrm{N}-\mathrm{V}}$ is negative as expected because $\mathrm{L}=\mathrm{NV}$ by definition. However, for this small variation of $\mathrm{L}$, not only $\Gamma_{\mathrm{N}-\mathrm{L}}$ but also $\Gamma_{\mathrm{V}-\mathrm{L}}$ are positive, indicating homogeneous mixing, i.e., smaller mean volume of droplets for more diluted cloud parcel. Figure 2 shows scatterplots of the correlation coefficient values for all segments. Remarkably, a majority of $\Gamma_{\mathrm{N}-\mathrm{L}}$ and $\Gamma_{\mathrm{V}-\mathrm{L}}$ values are larger than 0.5 , indicating significant correlation. As noted above, $\Gamma_{\mathrm{N}-\mathrm{V}}$ is positive in all segments except for 13 . These correlation coefficient values strongly support the homogeneous mixing mechanism. 
Mixing diagram has been also used in several previous studies to illustrate the entrainment and mixing mechanism. Its two axes are normalized number concentration $\left(N / N_{a}\right)$ and normalized mean volume $\left(\mathrm{V} / \mathrm{V}_{\mathrm{a}}\right)$, where the subscript a indicates the adiabatic value. The adiabatic $\mathrm{L}\left(\mathrm{L}_{\mathrm{a}}\right)$ can be defined as $\mathrm{L}_{\mathrm{a}}=\mathrm{N}_{\mathrm{a}} \mathrm{V}_{\mathrm{a}}$; then, the dilution ratio of $\mathrm{L}(=\alpha)$ is calculated as

$$
\alpha=\frac{\mathrm{L}}{\mathrm{L}_{\mathrm{a}}}=\frac{\mathrm{N}}{\mathrm{N}_{\mathrm{a}}} \frac{\mathrm{V}}{\mathrm{V}_{\mathrm{a}}}
$$

It is very difficult to find the adiabatic values because $\mathrm{W}$ and supersaturation can change continuously due to turbulent fluctuation of air and also by entrainment and mixing. For this reason, the maximum $\mathrm{N}\left(\mathrm{N}_{\mathrm{m}}\right)$ and $\mathrm{V}\left(\mathrm{V}_{\mathrm{m}}\right)$ are used as a proxy for the adiabatic values under the assumption that the less a cloud parcel is diluted, the more the parcel is close to being adiabatic. Figure 3 shows the droplet size distributions of the cloud parcels with $\mathrm{N}_{\mathrm{m}}$ in each of the 6 segments listed in Table 2. They are all mono-modal, suggesting that the high concentrations were not due to new droplet activation but presumably due to adiabaticity and thus minimal dilution.

Figure 4 shows the mixing diagrams of the 6 segments listed in Table 2. The two particular segments 67 and 81 in Figure $4 \mathrm{a}$ and $4 \mathrm{~b}$ are horizontal penetrations at an altitude of about $886 \mathrm{mb}$ on April 19, 2009. Most of the data clearly line up with a homogeneous mixing line as $\mathrm{N} / \mathrm{N}_{\mathrm{m}}$ decreases with the decrease of $\mathrm{V} / \mathrm{V}_{\mathrm{m}}$ (so called 'HM-like'). The mean $\mathrm{N}$ of these two segments $\left(364.2 \mathrm{~cm}^{-3}\right.$ and $\left.396.8 \mathrm{~cm}^{-3}\right)$ are similar to those of the other four segments. However, the mean $\varepsilon\left(25.03 \mathrm{~cm}^{2} \mathrm{~s}^{-3}\right.$ and $\left.11.34 \mathrm{~cm}^{2} \mathrm{~s}^{-3}\right)$, mean magnitude of $\mathrm{W}\left(0.93 \mathrm{~m} \mathrm{~s}^{-1}\right.$ and $\left.0.72 \mathrm{~m} \mathrm{~s}^{-1}\right)$ and standard deviation of vertical velocity $\left(0.64 \mathrm{~m} \mathrm{~s}^{-1}\right.$ and $\left.0.55 \mathrm{~m} \mathrm{~s}^{-1}\right)$ are much larger than those of the other four segments. Most segments that show similar data scatter patterns in the mixing diagram clearly have similar features. More noteworthy is that the 
altitudes of segments 67 and 81 were close to the cloud top. For marine stratocumulus clouds Yum et al. (2015) found that V and L were not correlated for penetrations near the cloud top, which led to their speculation that mixing of the entrained air near cloud top was inhomogeneous. The positive $\Gamma_{\mathrm{V}-\mathrm{L}}$ for segments 67 and 81 are therefore clearly in contrast.

The data scatter pattern in the two segments $(31,65)$ is difficult to be categorized (Fig. 4c and 4d), although they still belong to HM when classified in Table 1 . So we call them "vaguely HM." As shown in Table 2, the mean L of these two segments are 0.082 and $0.053 \mathrm{~g}$ $\mathrm{m}^{-3}$, which are a factor of two to three lower than those of segments 67 and 81 ; the magnitude of $\mathrm{W}$ is smaller and its variation (i.e., standard deviation) is also smaller. Moreover $\varepsilon$ is much smaller than those in segments 67 and 81 . These differences might be related to the fact that segments 31 and 65 were measured at altitudes of about $893 \mathrm{mb}$ and $905 \mathrm{mb}$, respectively. So they were closer to the cloud base than segments 67 and 81 . Importantly $\varepsilon$ tends to be larger at higher altitude (MacPherson and Isaac, 1997; Gerber et al., 2008) and the same trend is found in this study (not shown). The smaller mean L and V for segments 31 and 65 should also be due to lower cloud altitudes. Noteworthy is that only these two segments $(31,65)$ among the 93 segments that belong to HM in Table 1 show a data scatter pattern that is hardly expected from HM.

As noted above, 13 segments show a relatively small variation of $\mathrm{L}$, and therefore roughly it can be said that data scatter along iso- $\alpha$ lines. Two examples are shown in Fig. $4 \mathrm{e}$ and $4 \mathrm{f}$ (segment 27 and 84): both $\mathrm{N}$ and $\mathrm{V}$ vary widely, but the variation of $\mathrm{L}$ is comparatively small. Similar data scatters were already observed in Palowska et al. (2000) and Yum et al. (2015). The $\mathrm{V}_{\mathrm{m}}$ in segments 27 and 84 are smaller than those in the other four segments in Fig. 4. If updraft speed in cloud parcels varies greatly in the initial growth stage 
of a cloud, the number of activated cloud droplets could also vary a lot. If L is similar in these cloud parcels, higher concentration of activated cloud droplets indicates smaller mean volume

257

258

259 260

261

262

263

264

265

266

268

269

270

271

272

273

of the droplets since $\mathrm{L}=\mathrm{NV}$. So $\Gamma_{\mathrm{N}-\mathrm{V}}<0$. The important point here is that $\Gamma_{\mathrm{V}-\mathrm{L}}>0$ for all 13

segments. That is, the parcels with more liquid water had larger mean volume of the droplets in these segments, showing HM-like feature although there was relatively small variation of L.

\section{Transition length and Transition scale number}

The importance of turbulence in entrainment and mixing processes was emphasized in many studies. Lehmann et al. (2009) suggested that the reaction time scale $\left(\tau_{\mathrm{r}}\right)$ is more appropriate than $\tau_{\mathrm{e}}$ in calculating the Damköhler number:

$$
\mathrm{Da}=\frac{\tau_{\mathrm{m}}}{\tau_{\mathrm{e}}} \rightarrow \frac{\tau_{\mathrm{m}}}{\tau_{\mathrm{r}}}
$$

because the variation of saturation ratio due to droplet evaporation is considered when estimating $\tau_{\mathrm{r}}$, while it is assumed constant when estimating $\tau_{\mathrm{e}}$. However, variations of droplet sizes and saturation ratio occur simultaneously. Thus, $\tau_{\mathrm{r}}$ was calculated numerically by solving the two relevant differential equations interactively until reaching the time either when the droplets are evaporated completely or when the saturation ratio reaches 0.995 . Meanwhile, $\tau_{\mathrm{m}}$, the numerator in the expression of the Damköhler number, is a function of the mixing length scale $\mathrm{L}_{\mathrm{E}}$ and $\varepsilon$,

$$
\tau_{\mathrm{m}}=\left(\frac{\mathrm{L}_{\mathrm{E}}^{2}}{\varepsilon}\right)^{\frac{1}{3}}
$$


274 The larger $\varepsilon$ is, the smaller $\tau_{\mathrm{m}}$ becomes. This means that entrained air and cloudy air can be 275 mixed more rapidly when $\varepsilon$ is larger. $\tau_{\mathrm{m}}$ would also change greatly depending on $\mathrm{L}_{\mathrm{E}}$. However, 276 there is no clear agreement on a proper value of $L_{E}$ because the actual size of an entrained air 277 parcel varies significantly. Therefore, Lehmann et al. (2009) proposed the transition length $278\left(\mathrm{~L}^{*}\right)$ to solve this ambiguity. $\mathrm{L}^{*}$ indicates the length scale when the Damköhler number 279 becomes 1 and is calculated as,

$$
L^{*}=\varepsilon^{\frac{1}{2}} \tau_{r^{\frac{3}{2}}}
$$

280 It is expected that IM would likely occur when $\mathrm{L}_{\mathrm{E}}$ is longer than $\mathrm{L}^{*}$. If the opposite is the case, 281 HM would likely occur. the Kolmogorov length scale $(\eta)$,

$$
\mathrm{N}_{\mathrm{L}}=\frac{\mathrm{L}^{*}}{\eta}
$$

284 Similarly it is expected that HM would occur more frequently with larger $\mathrm{N}_{\mathrm{L}}$. Lu et al. (2011) proposed that when $\mathrm{N}_{\mathrm{L}}$ is greater than 50 , $\mathrm{HM}$ could dominate.

We calculated $\mathrm{L}^{*}$ and $\mathrm{N}_{\mathrm{L}}$ for all segments. T, pressure (p) and $\mathrm{RH}$ value at the top of the EIL were assumed to be those of entrained air. Segments 67 and 81 have an average $\mathrm{N}_{\mathrm{L}}$ of 35.2 and 33.3, respectively, as summarized in Table 2, which are smaller than the threshold value of 50 suggested by Lu et al. (2011). Meanwhile, segments 31 and 65 that shows vague HM signature have an average $\mathrm{N}_{\mathrm{L}}$ of 4.7 and 2.3, respectively. These are in accordance with the prediction that the larger the scale number is, the more the mixing becomes homogeneous.

On the other hand, $\mathrm{L}^{*}$ are about $7.5 \mathrm{~cm}$ for segments 67 and 81 , but for segments 31 and 65 , 
they are about $1 \mathrm{~cm}$ (Table 2). These results also suggest that $\mathrm{HM}$ would be more likely for segments 67 and 81 than segments 31 and 65. Segments 27 and 84, for which the data in the mixing diagram roughly follow iso- $\alpha$ lines, have values of $\mathrm{W}$ and $\varepsilon$ similar to those for segments 31 and 65 . Their similarity continues for $\mathrm{N}_{\mathrm{L}}$ and $\mathrm{L}^{*}$, too.

Overall the range of $\mathrm{N}_{\mathrm{L}}$ for HM-like segments in Table 1 is $10-60$. The $\mathrm{L}^{*}$ of $5-12 \mathrm{~cm}$ for these segments are in agreement with that for the homogeneous mixing case in Lehmann et al. (2009). For the segments of vaguely $\mathrm{HM}$ and iso- $\alpha$ lines, $\mathrm{N}_{\mathrm{L}}$ and $\mathrm{L}^{*}$ are much smaller. Figure 5 shows $\mathrm{L}^{*}$ and $\mathrm{N}_{\mathrm{L}}$ for all segments, where the black and red circles indicate HM-like and the rest, respectively, as classified in Table 1. A separation between the two groups is rather clearly shown. Perhaps the $\mathrm{N}_{\mathrm{L}}$ value of about 10 would be a good threshold for homogeneous mixing in our dataset but this value is significantly different from the threshold value, 50, suggested by Lu et al. (2011).

To understand this difference, the variables that greatly affect $\mathrm{N}_{\mathrm{L}}$ are examined. Figure $6 \mathrm{a}$ and $6 \mathrm{~b}$ show the variation of $\mathrm{N}_{\mathrm{L}}$ as a function of $\mathrm{N}, \mathrm{V}$, and $\varepsilon$ under the condition of a fixed $\mathrm{V}$ of $0.524 \times 10^{3} \mu \mathrm{m}^{3}$ (i.e., $\mathrm{D}_{\mathrm{v}}$ of $10 \mu \mathrm{m}$ ) and a fixed $\mathrm{N}$ of $300 \mathrm{~cm}^{-3}$, respectively. It is obvious that $\mathrm{N}_{\mathrm{L}}$ varies greatly with the change of $\varepsilon$ and $\mathrm{V}$ but insignificantly with $\mathrm{N}$. Lu et al. (2011) used $1 \mathrm{~Hz}$ cloud microphysics data (100 m spatial resolution). To match the resolution, $24 \mathrm{~Hz}$ $\varepsilon$ data were averaged to $1 \mathrm{~Hz}$. However, this may cause the overestimation of $\mathrm{N}_{\mathrm{L}}$, necessarily because $\mathrm{N}_{\mathrm{L}}$ is proportional to $\varepsilon^{\frac{3}{4}}$. Table 3 compares the $\mathrm{N}_{\mathrm{L}}$ values calculated with the time resolutions of 10 and $1 \mathrm{~Hz}$ for $\varepsilon$ and the droplet size distribution, only for the cloud segments longer than $5 \mathrm{~km}$ in the data obtained on April 19. As expected, $\mathrm{N}_{\mathrm{L}}$ is larger for $1 \mathrm{~Hz}$ and the mean ratio of $\left(\mathrm{N}_{\mathrm{L}(10 \mathrm{~Hz})} / \mathrm{N}_{\mathrm{L}(1 \mathrm{~Hz})}\right)$ is 0.88 . 
Figure $6 \mathrm{c}$ shows the variation of $\mathrm{N}_{\mathrm{L}}$ for a range of $\mathrm{RH}$ of entrained air under a fixed $\varepsilon$ of $100 \mathrm{~cm}^{2} \mathrm{~s}^{-3} . \mathrm{N}_{\mathrm{L}}$ decreases as RH decreases because the drier the entrained air is, the faster the cloud parcel could evaporate before mixing is completed. However, variation due to RH change is not as sensitive as that due to $\varepsilon$ change. If the air close to the bottom of an EIL is entrained into the cloud by small eddies, the entrained air would be almost saturated and its temperature would have little difference with that of cloudy air. Then droplets could evaporate minimally and there would be little change in droplet size distribution in the mixed cloud parcel and therefore mixing would look like inhomogeneous (Gerber et al., 2005). However, Fig. 6c suggests that as $\mathrm{RH}$ of entrained air increases, $\mathrm{N}_{\mathrm{L}}$ increases, suggesting increased likelihood of homogeneous mixing. This means that $\mathrm{N}_{\mathrm{L}}$ cannot be applied to all situations as a single appropriate parameter for predicting the mixing mechanism.

\section{Discussion and Conclusion}

In this study, we tried to analyze what type of mixing mechanism dominantly occurred in the continental stratocumulus clouds observed during the RACORO campaign. The results suggested that HM occurred dominantly in 93 of 110 cloud segments analyzed here, when classified based on the relevant correlation coefficient values. Among the 93 segments, only two deviated from the expected data scatter pattern of HM. Even for the segments that showed relatively small variation of $\mathrm{L}$, the correlation between $\mathrm{L}$ and $\mathrm{V}$ was positive (i.e., smaller mean volume of droplets for more diluted parcels), which supports HM. Several factors can be considered in relation to the dominance of the features that support HM. 
The first factor to be examined is the environmental conditions. The vertical profiles of the thermodynamic variables were very different from the ones observed for the marine stratocumulus clouds analyzed in Yum et al. (2015), where it was much warmer (temperature difference of about $\left.15{ }^{\circ} \mathrm{C}\right)$ and very dry $(\mathrm{RH}<40 \%)$ above the cloud top. The temperature difference between the air above the cloud top and the cloudy air was merely about $4{ }^{\circ} \mathrm{C}$ and RH was relatively high above the cloud top (60-70\%) for the RACORO stratocumulus clouds. Clearly HM would be more prevalent when the entrained air is more humid. Moreover, $\varepsilon$, another important factor that determine mixing mechanism, was higher in this study than estimated in Yum et al. (2015). Moreover, the relevant scale parameters, $\mathrm{L}^{*}$ and $\mathrm{N}_{\mathrm{L}}$, shown in Fig. 5, are much larger than those estimated in Yum et al. (2015): 95\% percentile values of L* and $\mathrm{N}_{\mathrm{L}}$ were about $1 \mathrm{~cm}$ and 10 , respectively. These differences strongly suggest that $\mathrm{HM}$ was more likely to occur for the continental stratocumulus clouds measured during the RACORO campaign.

An important factor to consider is the spatial resolution of the data. Lu et al. (2011) did similar research, using the aircraft measurement data obtained over the region of the RACORO campaign. They reported that IM occurred dominantly in most cases. In their study, however, $1 \mathrm{~Hz}$ data were used, which corresponded to a spatial resolution of about $100 \mathrm{~m}$. The problem with this coarse resolution is that cloudy samples may not always be composed of entirely cloudy air. When cloudy samples were in fact a mixture of cloudy and droplet-free air, these samples would be misinterpreted as having diluted concentration, but this does not affect the calculation of mean volume of droplets. So if a cloud segment contains significant number of such samples, $\mathrm{N}$ would vary much but $\mathrm{V}$ might not, falsely indicating IM (e.g., Burnet and Brenguier, 2007; Lu et al., 2011; Lu et al., 2014). Consistently Lu et al. (2014) 
also demonstrated that the homogeneous mixing degree tended to be smaller over a longer averaging spatial scale. On the other hand the spatial resolution was about $5 \mathrm{~m}$ for the RACORO data analyzed in this study because of slower aircraft speed. So it is much less likely to have the problem of coarse resolution described here.

Another factor to discuss is the effect of vertical circulation mixing. Yum et al. (2015) found that for the maritime stratocumulus clouds over the southeastern Pacific Ocean the mixing diagram and correlation coefficient analyses indicated dominant HM, while relevant scale parameters $\left(\mathrm{L}^{*}\right.$ and $\left.\mathrm{N}_{\mathrm{L}}\right)$ indicated IM. They speculated that this discrepancy was caused by the modulation of cloud microphysics due to vertical circulation mixing as also suggested by Wang et al. (2009) for the marine stratocumulus clouds over the northeastern Pacific Ocean. It is difficult to identify evidence for vertical circulation mixing, but at least we can examine how cloud microphysical parameters vary with W. Figure 7 compares the time variations of the cloud microphysical variables ( $\mathrm{L}, \mathrm{V}$, and standard deviation of $\mathrm{D}\left(\sigma_{\mathrm{D}}\right)$ ) with that of $\mathrm{W}$ in segments 67 and 31. In segment 67, downdraft and updraft appear in turn, like a wave, and they correlate well with $\mathrm{L}, \mathrm{V}$, and $\sigma_{\mathrm{D}}$. Downdraft is dominant in the regions where $\mathrm{L}$ is small perhaps due to the entrainment of dryer and warmer air from above the cloud top. In addition $\mathrm{V}$ is small but $\sigma_{\mathrm{D}}$ is large in these regions. In fact, there is a significant difference in droplet size distribution between $\mathrm{W}>0$ and $\mathrm{W}<0$ regions, as shown in Fig. 8. Although $\mathrm{N}$ is lower, the number concentration of small droplets $(\mathrm{D}<10 \mu \mathrm{m})$ is higher in the downdraft than in the updraft regions. This reduction of $\mathrm{V}$ and eventual broadening toward smaller diameters might be caused by droplet evaporation due to adiabatic warming during descent. 
support of the idea of vertical circulation mixing. However, this is not always the case as shown in Fig. 7b and Fig. 9a for segment 31.

To initiate vertical circulation, however, evaporative cooling generated by mixing of entrained air and cloudy air near the cloud top should be strong enough to cause buoyancy instability and reversal (Lilly, 1968; Randall, 1980; Deardorff, 1980). To check it, the virtual potential temperature, $\theta_{\mathrm{v}}$, defined as (Deardorff, 1980),

$$
\theta_{\mathrm{v}}=\theta\left(1+0.61 \mathrm{q}_{\mathrm{v}}-\mathrm{q}_{\mathrm{l}}\right)
$$

where $\mathrm{q}_{\mathrm{v}}$ is the vapor mixing ratio and $\mathrm{q}_{1}$ is the liquid water mixing ratio, can be examined. In Fig. 9b, L and $\theta_{\mathrm{v}}$ is negatively correlated for segment 67: $\theta_{\mathrm{v}}$ is higher for more diluted parcels. However, more diluted parcels tends to descend in Fig. 9a. Combined, it means that more buoyant parcels tends to descend. This contradictory result is suspected to be related to the limitation of temperature measurement during the RACORO campaign as mentioned earlier. Without a reverse flow setup, the sensor element of the Rosemount probe was directly exposed to cloud particles and therefore highly susceptible to wetting and subsequent cooling due to evaporation. The degree of wetting is known to depend on liquid water content (Lenschow and Pennell, 1974; Heymsfield et al., 1979; LeMone, 1980; Lawson and Cooper, 1990). Indeed, with a close examination we found that $T$ decreased rapidly when entering into the cloud and then slowly recovered after exiting the cloud (not shown). It can be speculated that higher $\theta_{\mathrm{v}}$ for lower L for segment 67 in Fig. $9 \mathrm{~b}$ was due to less wetting and therefore less evaporative cooling. It is puzzling that this is not the case for segment 31 in Fig. 9b, which shows no correlation between $\mathrm{L}$ and $\theta_{\mathrm{v}}$. Nevertheless, it is unfortunately certain that temperature variables cannot be discussed in conjunction with vertical circulation mixing. It can also be suggested that the temperature difference between above the cloud top and in 
cloud of $\sim 4{ }^{\circ} \mathrm{C}$ might actually be an overestimation; i.e., actual difference might have been

smaller.

In a nutshell, the environmental conditions, such as differences of temperature and humidity across the cloud top, turbulent dissipation rate and scale parameters $\left(\mathrm{L}^{*}\right.$ and $\left.\mathrm{N}_{\mathrm{L}}\right)$, that can characterize the mixing mechanism, suggest more prevalent occurrence of homogenous mixing in the continental stratocumulus clouds analyzed in this study than in the maritime stratocumulus clouds analyzed in Yum et al. (2015). The fact that segments 67 and 81 , which were close to the cloud top, did show a data scatter pattern of homogeneous mixing (Figs. 4a and $\mathrm{b}$ ) and thus a strong positive correlation between $\mathrm{N}$ and $\mathrm{V}$ and also $\mathrm{L}$ and $\mathrm{V}$, seems to indicate that homogeneous mixing indeed occurred after the air from above the cloud top was entrained. This is different from Yum et al. (2015), where N and V or L and V showed no correlation for a near cloud top penetration. This was the reason why they speculated that the mixing itself near the cloud top was actually inhomogeneous as the scale parameters indicated but the cloud microphysical relationships in mid-level of clouds changed during vertical circulation mixing to suggest homogeneous mixing. Perhaps vertical circulation mixing also did occur in the continental stratocumulus clouds analyzed here (Fig. 9a) to enhance the positive relationships between $\mathrm{N}$ and $\mathrm{V}$ and between $\mathrm{L}$ and $\mathrm{V}$ already generated by homogeneous mixing of the entrained air.

The dominant trait of homogeneous mixing in this study were in contrast to several 424 previous studies that suggested inhomogeneous mixing. To note is that they used coarse resolution data and therefore could have been subject to inhomogeneous mixing bias explained earlier (Pawlowska et al., 2000; Burnet and Brenguier, 2007; Gerber et al., 2008;

427 Lu et al., 2011). Demonstrated in this study was that the transition scale number, $\mathrm{N}_{\mathrm{L}}$, was 
estimated to be significantly larger for coarser resolution (Table 3), suggesting greater

429

430

431

432

433

434

435

436

437

438

439

440

441

442

443

444

445

446

447

448

449

450

451

452

453 likelihood of homogeneous mixing. Emphasis should be placed on the importance of high

spatial resolution data when it comes to the analysis of entrainment and mixing problem. In

that sense, the recent study by Beals et al. (2105) is promising that reported the power of very

high resolution $(\sim 1 \mathrm{~cm})$ holographic imaging as a tool to investigate detailed picture of cloud droplet distribution.

Acknowledgments. This work is funded by the Korea Meteorological Administration Research and Development Program [Grant KMIPA 2015-2061]. Data used in this article are from the U.S. Department of Energy ARM Aerial Facility's RACORO campaign (http://www.arm.gov/). Liu is supported by the Atmospheric System Research (ASR) program of the United State's Department of Energy. Lu is supported by the National Natural Science Foundation of China (No. 91537108).

\section{References}

Andrejczuk, M., Gadian, A., Blyth, A., 2014. Numerical simulations of stratocumulus cloud response to aerosol perturbation. Atmos. Res. 140-141, 76-84.

Baker, M.B., Corbin, R.G., Latham, J., 1980. The influence of entrainment on the evolution of cloud-droplet spectra: I . A model of inhomogeneous mixing. Q. J. R. Meteorol. Soc. 106, 581-598.

Beals, M.J., Fugal, J.P., Shaw, R.A., Lu, J., Spuler, S.M., Stith, J.L., 2015. Holographic measurements of inhomogeneous cloud mixing at the centimeter scale. Science. 350, 8790. 
Beard, K.V., Ochs, H.T., 1993. Warm-rain initiation: An overview of microphysical mechanisms. J. Appl. Meteorol. 32, 608-625.

Burnet, F., Brenguier, J.L., 2007. Observational study of the entrainment-mixing process in warm convective clouds. J. Atmos. Sci. 64, 1995-2011.

Deardorff, P.G., 1980. Cloud-top entrainment instability. J. Atmos. Sci. 37, 131-147.

Deng, Z., Zhao, C., Zhang, Q., Huang, M., Ma, X., 2009. Statistical analysis of microphysical properties and the parameterization of effective radius of warm clouds in Beijing area. Atmos. Res., 93(4), 888-896, doi:10.1016/j.atmosres.2009.04.011.

Devenish, B.J., Bartello, P., Brenguier, J.L., Collins, L.R., Grabowski, W.W., IJzermans, R.H.A., Malinowski, S.P., Reeks, M.W., Vassilicos, J.C., Wangi, L.-P., Warhaft, Z., 2012. Droplet growth in warm turbulent clouds. Q. J. R. Meteorol. Soc. 138, 1401-1429.

Diskin, G.S., Podolske, J.R., Sachse, G.W., Slate, T.A., 2002. Open-path airborne tunable diode laser hygrometer. paper presented at Proceedings of SPIE, Seattle, Wash.

Gerber, H., Malinowski, S.P., Brenguier, J.L., Burnet, F., 2005. Holes and entrainment in stratocumulus. J. Atmos. Sci. 62, 443-459.

Gerber, H., Frick, G.M., Jensen, J.B., Hudson, J. 2008. Entrainment, mixing, and microphysics in trade-wind cumulus. J. Meteorol. Soc. Jpn. 86A, 87-106.

Grabowski, W.W., Wang, L.P., 2013. Growth of cloud droplets in a turbulent environment. Annu. Rev. Fluid Mech. 45, 293-324.

Haman, K.E., Malinowski, S.P., Kurowski, M.J., Gerber, H., Brenguier, J.L., 2007. Small scale mixing processes at the top of a marine stratocumulus-A case study. Q. J. R. Meteorol. Soc. 133, 213-226.

Heymsfield, A.J., Dye, J.E., Biter, C.J., 1979. Overestimates of entrainment from wetting of aircraft temperature sensors in cloud. J. Appl. Meteorol. 18, 92-95.

Hudson, J.G., Yum, S.S., 1997. Droplet spectral broadening in marine stratus. J. Atmos. Sci. $54,2642-2654$.

Lábó, E., Geresdi, I., 2016. Study of longwave radiative transfer in stratocumulus clouds by using bin optical properties and bin microphysics scheme. Atmos. Res. 167, 61-76. 
Lawson, R.P., Cooper, W.A., 1990. Performance of some airborne thermometers in clouds. J. Atmos. Oceanic Technol. 7, 480-494.

Lehmann, K., Siebert, H., Shaw, R.A., 2009. Homogeneous and inhomogeneous mixing in cumulus clouds: Dependence on local turbulence structure. J. Atmos. Sci. 66, 36413659.

LeMone, M.A., 1980. On the difficulty of measuring temperature and humidity in cloud: Comments on "shallow convection on day 261 of GATE: Mesoscale arcs." Mon. Wea. Rev. 108, 1702-1707.

Lenschow, D.H., Pennell, W.T., 1974. On the measurement of in-cloud and wet-bulb temperatures from an aircraft. Mon. Wea. Rev. 102, 447-454.

Lilly, D.K., 1968. Models of cloud-topped mixed layers under a strong inversion. Q. J. R. Meteorol. Soc. 94, 292-309.

Liu, Y., Hallett, J., 1998. On size distributions of cloud droplets growing by condensation: A new conceptual model. J. Atmos. Sci. 55, 527-536.

Liu, Y., Daum, P.H., Hallett, J., 2002. A generalized systems theory for the effect of varying fluctuations on cloud droplet size distributions. J. Atmos. Sci. 59, 2279-2289.

Lu, C., Liu, Y., Niu, S., 2011. Examination of turbulent entrainment-mixing mechanisms using a combined approach. J. Geophys. Res. 116, D20207.

Lu, C., Liu, Y., Niu, S., Endo, S., 2014. Scale dependence of entrainment-mixing mechanisms in cumulus clouds. J. Geophys. Res. Atmos. 119, doi:10.1002/2014JD022265.

MacPherson, J.I., Isaac, G.A., 1977. Turbulent characteristics of some Canadian cumulus clouds. J. Appl. Meteorol. 16, 81-90.

Paluch, I.R., 1979. The entrainment mechanism in Colorado cumuli. J. Atmos. Sci. 36, 24672478.

Pawlowska, H., Brenguier, J.L., Burnet, F., 2000. Microphysical properties of stratocumulus clouds. Atmos. Res. 55, 15-33. 
Podolske, J.R., Sachse, G.W., Diskin, G.S., 2003. Calibration and data retrieval algorithms for the NASA Langley/Ames Diode Laser Hygrometer for the NASA Transport and Chemical Evolution Over the Pacific (TRACE-P) mission. J. Geophys. Res. 108(D20), 8792, doi:10.1029/2002JD003156.

Poellot, M.R., Grainger, C.A., 1991. A comparison of several airborne measures of turbulence. paper presented at the 4th International Conference of the Aviation Weather Systems, Am. Meteorol. Soc., Paris.

Randall, D.A., 1980. Conditional instability of the first kind upside-down. J. Atmos. Sci. 37, $125-130$.

Rogers, R.R., Yau, M.K., 1989. A Short Course in Cloud Physics. Butterworth Heinemann, Burilingston, MA, USA.

Vogelmann, A.M., et al., 2012. RACORO extended-term aircraft observations of boundary layer clouds. Bull. Am. Meteorol. Soc. 93, 861-878.

Wang, J., Daum, P.H., Yum, S.S., Liu, Y., Senum, G.I., Lu, M.L., Seinfeld, J.H., Jonsson, H., 2009. Observations of marine stratocumulus microphysics and implications for processes controlling droplet spectra: Results from the Marine Stratus/Stratocumulus Experiment. J. Geophys. Res. 114, D18210, doi:10.1029/2008JD011035.

Wang, Y., Geerts, B., 2009. Estimating the Evaporative Cooling Bias of an Airborne Reverse Flow Thermometer. J. Atmos. Oceanic Technol. 26, doi:10.1175/2008JTECHA1127.1.

Warner, J., 1973. The microstructure of cumulus cloud: Part IV. The effect on the droplet spectrum of mixing between cloud and environment. J. Atmos. Sci. 30, 256-261.

Yang, W., Marshak, A., McBride, P.J., Chiu, J.C., Knyazikhin, Y., Schmidt, K.S., Flynn, C., Lewis, E.R., Eloranta, E.W., 2016. Observation of the spectrally invariant properties of clouds in cloudy-to-clear transition zones during the MAGIC field campaign. Atmos. Res. 182, 294-301.

Yum, S.S., Hudson, J.G., 2001. Cloud microphysical relationships in warm clouds. Atmos. Res. 57, 81-104.

Yum, S.S., Hudson, J.G., 2005. Adiabatic predictions and observations of cloud droplet spectral broadness. Atmos. Res. 73, 203-223. 
538 Yum, S.S., Wang, J., Liu, Y., Senum, G., Springston, S., McGraw, R., Yeom, J.M., 2015. 539 Cloud microphysical relationships and their implication on entrainment and mixing 540 mechanism for the stratocumulus clouds measured during the VOCALS project. J. 541 Geophys. Res. Atmos. 120, 5047-5069.

542 
543 Table 1. Number of cloud segments that show expected cloud microphysical relationships for 544 some important microphysical processes. Here HM indicates homogeneous mixing and IM 545 indicates inhomogeneous mixing.

\begin{tabular}{ccccc}
\hline Process & $\Gamma_{\mathrm{N}-\mathrm{V}}$ & $\Gamma_{\mathrm{N}-\mathrm{L}}$ & $\Gamma_{\mathrm{V}-\mathrm{L}}$ & No. of segments \\
\hline $\mathrm{HM}$ & $>0$ & $>0$ & $>0$ & 93 \\
$\mathrm{IM}$ & $\sim 0$ & $>0$ & $\sim 0$ & 0 \\
Small variation in L & $<0$ & $>0$ & $>0$ & 13 \\
Not classified & $\cdot$ &. & $\cdot$ & 4 \\
\hline
\end{tabular}

546

547

548

549 
Table 2. Values of important parameters for the selected six segments. Here STD indicates standard deviation.

\begin{tabular}{|c|c|c|c|c|c|c|}
\hline Segment number & 67 & 81 & 31 & 65 & 27 & 84 \\
\hline Penetration Time (s) & 46 & 100 & 110 & 62 & 20 & 33 \\
\hline Mean N $\left(\mathrm{cm}^{-3}\right)$ & 364.2 & 396.8 & 394.0 & 368.4 & 340.9 & 247.8 \\
\hline Mean $\mathrm{L}\left(\mathrm{g} \mathrm{m}^{-3}\right)$ & 0.183 & 0.213 & 0.082 & 0.053 & 0.045 & 0.043 \\
\hline Mean $\vee\left(\mu \mathrm{m}^{3}\right)$ & 462.0 & 511.7 & 199.4 & 129.6 & 128.2 & 170.3 \\
\hline Mean $\varepsilon\left(\mathrm{cm}^{2} \mathrm{~s}^{-3}\right)$ & 25.03 & 11.34 & 5.26 & 1.94 & 3.21 & 2.76 \\
\hline STD $\varepsilon\left(\mathrm{cm}^{2} \mathrm{~s}-3\right)$ & 75.33 & 23.38 & 19.13 & 8.48 & 9.48 & 6.19 \\
\hline Mean $W\left(\mathrm{~m} \mathrm{~s}^{-1}\right)$ & 0.93 & 0.72 & 0.44 & 0.50 & 0.42 & 0.36 \\
\hline STD W $\left(\mathrm{m} \mathrm{s}^{-1}\right)$ & 0.64 & 0.55 & 0.39 & 0.33 & 0.25 & 0.31 \\
\hline Mean transition scale number $\left(\mathrm{N}_{\mathrm{L}}\right)$ & 35.2 & 33.3 & 4.7 & 2.3 & 4.4 & 5.3 \\
\hline Mean transition length $\left(\mathrm{L}^{\star}\right)(\mathrm{cm})$ & 7.1 & 7.8 & 1.3 & 0.7 & 1.4 & 1.7 \\
\hline dominant process & HM & HM & Vaquely HM & Vaquely HM & Iso- $\alpha$ line & Iso- $\alpha$ line \\
\hline
\end{tabular}

551 
555 Table 3. Comparison of the transition scale number calculated with $10 \mathrm{~Hz}$ and $1 \mathrm{~Hz}$ data for 55614 selected long cloud segments.

\begin{tabular}{ccccc}
\hline $\begin{array}{c}\text { Segment } \\
\text { number }\end{array}$ & Length of Cloud segments $(\mathrm{Km})$ & $\mathrm{N}_{\mathrm{L}}(10 \mathrm{~Hz})$ & $\mathrm{N}_{\mathrm{L}}(1 \mathrm{~Hz})$ & $\mathrm{N}_{\mathrm{L}}(10 \mathrm{~Hz}) / \mathrm{N}_{\mathrm{L}}(1 \mathrm{~Hz})$ \\
\hline 26 & 7.9 & 10.1 & 11.5 & 0.88 \\
27 & 5.5 & 4.4 & 5.0 & 0.88 \\
31 & 5.5 & 4.7 & 5.3 & 0.89 \\
32 & 7.4 & 3.7 & 4.8 & 0.77 \\
48 & 16.1 & 8.9 & 10.1 & 0.88 \\
56 & 5.6 & 31.0 & 35.4 & 0.88 \\
62 & 13.6 & 11.5 & 13.5 & 0.85 \\
63 & 21.7 & 16.8 & 18.7 & 0.90 \\
64 & 5.1 & 10.5 & 12.2 & 0.86 \\
73 & 7.1 & 16.5 & 19.6 & 0.84 \\
82 & 12.7 & 20.8 & 22.5 & 0.92 \\
85 & 6.5 & 13.0 & 15.3 & 0.85 \\
88 & 20.5 & 20.2 & 22.1 & 0.91 \\
94 & 6.9 & 31.8 & 35.5 & 0.90 \\
\hline Mean & 10.1 & 14.6 & 16.5 & 0.88 \\
\hline
\end{tabular}

557 

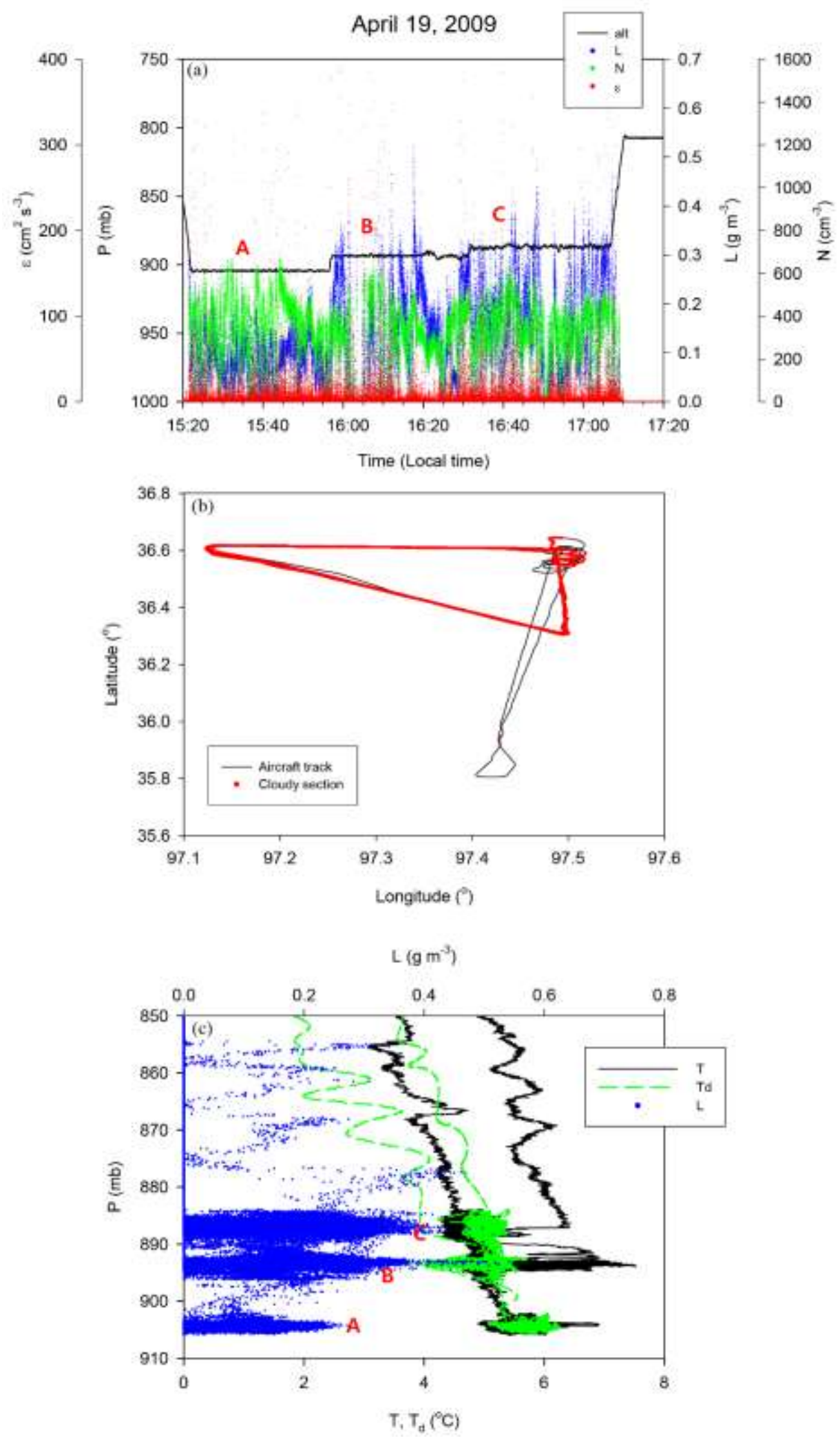

560 Figure 1. (a) Temporal variations of flight altitude, liquid water content (L), droplet number 561 concentration $(\mathrm{N})$, and turbulent dissipation rate $(\varepsilon)$ on 19 April 2009, (b) aircraft flight tracks, and (c) vertical profiles of $\mathrm{T}, \mathrm{T}_{\mathrm{d}}$, and $\mathrm{L}$, measured on the April 19 flight. In (b) cloudy sections are marked with red circles. 


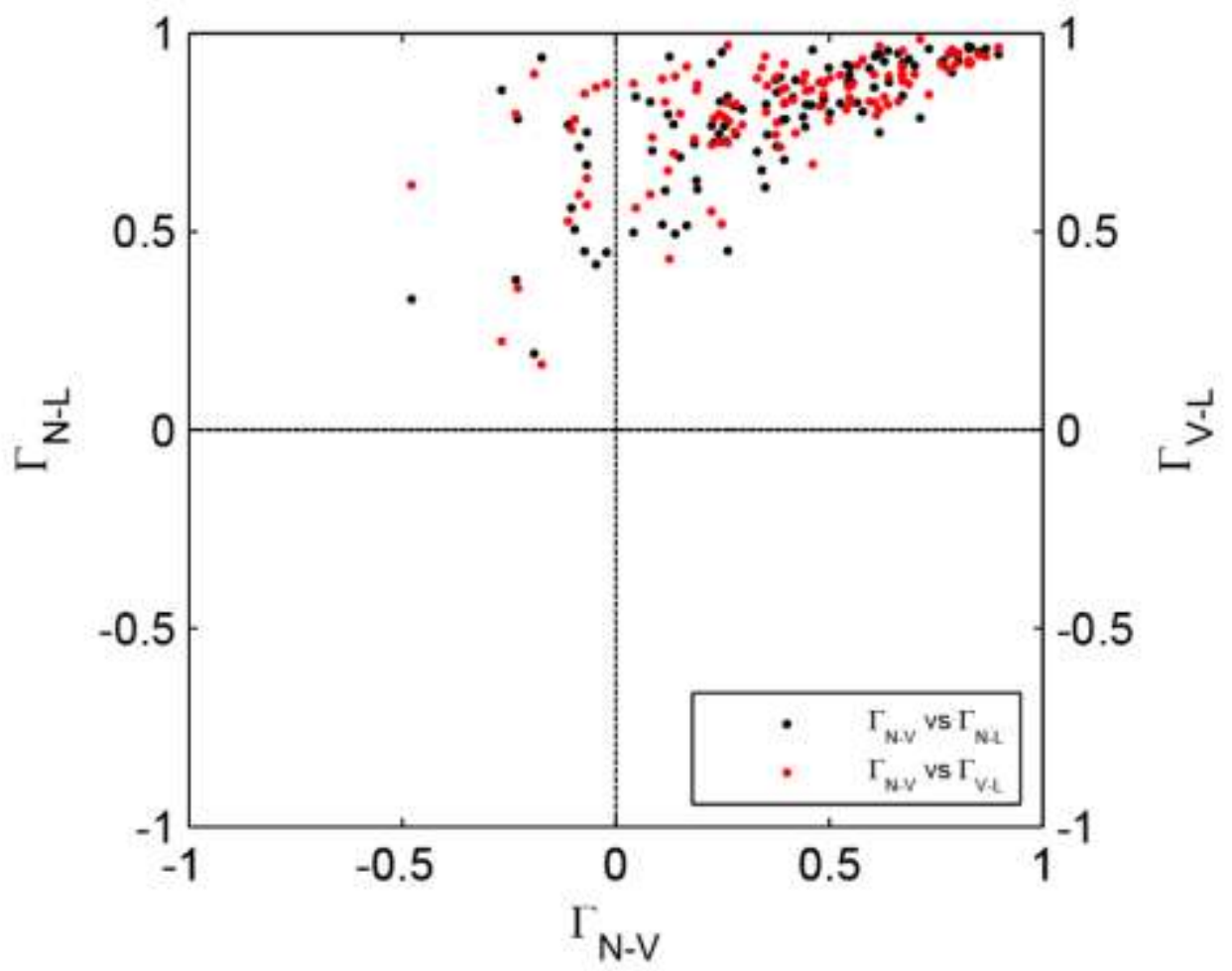

564

565 Figure 2. Scatterplots of $\Gamma_{\mathrm{N}-\mathrm{V}}$ versus $\Gamma_{\mathrm{N}-\mathrm{L}}$ (black) and $\Gamma_{\mathrm{N}-\mathrm{V}}$ versus $\Gamma_{\mathrm{V}-\mathrm{L}}$ (red) for all segments.

566

567

568

569

570

571

572

573 


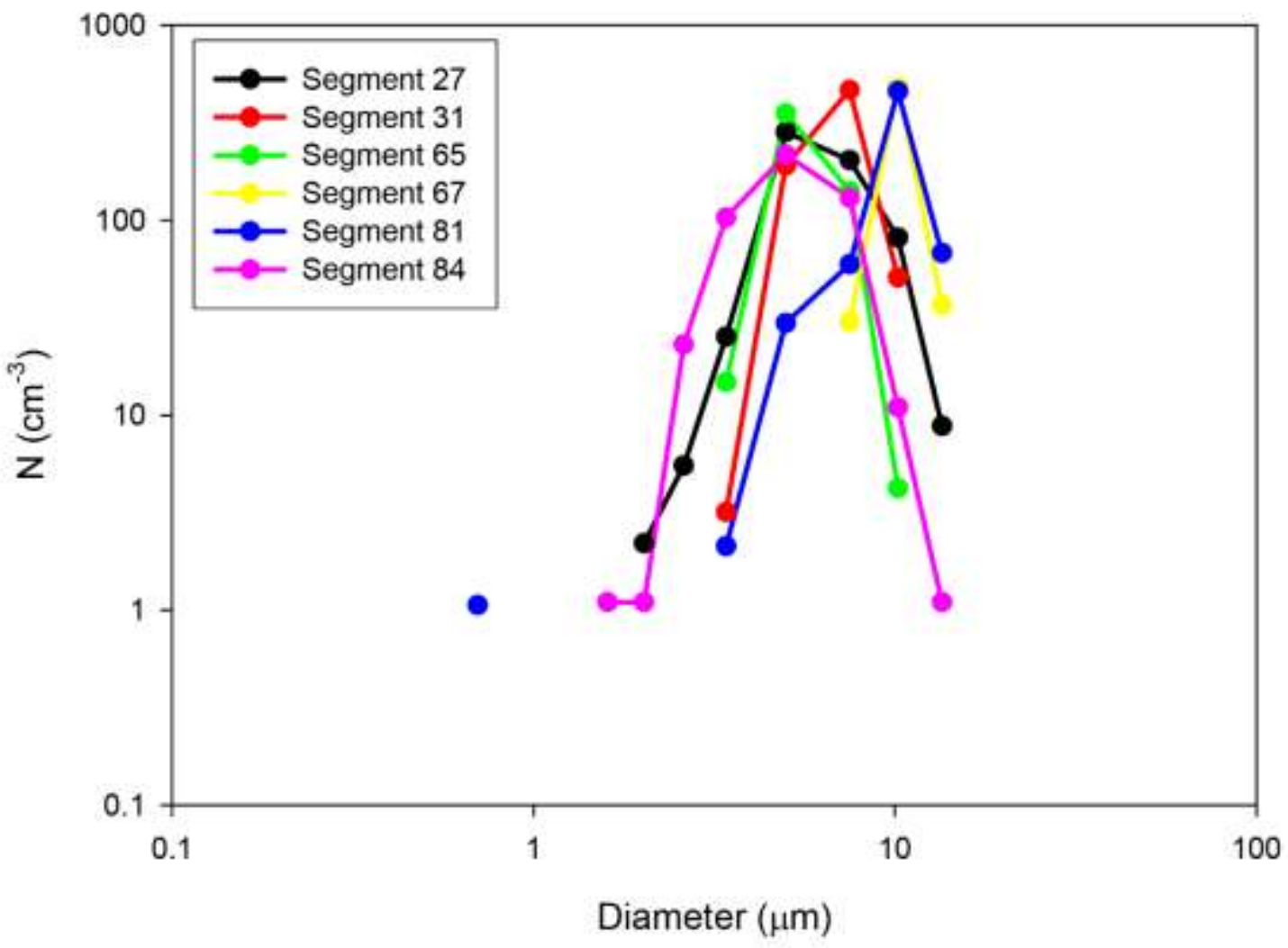

574

575 Figure 3. Droplet size distributions of the cloud parcels with the maximum droplet number 576 concentrations for each of the segments $27,31,65,67,81$, and 84 .

577

578

579

580

581

582 

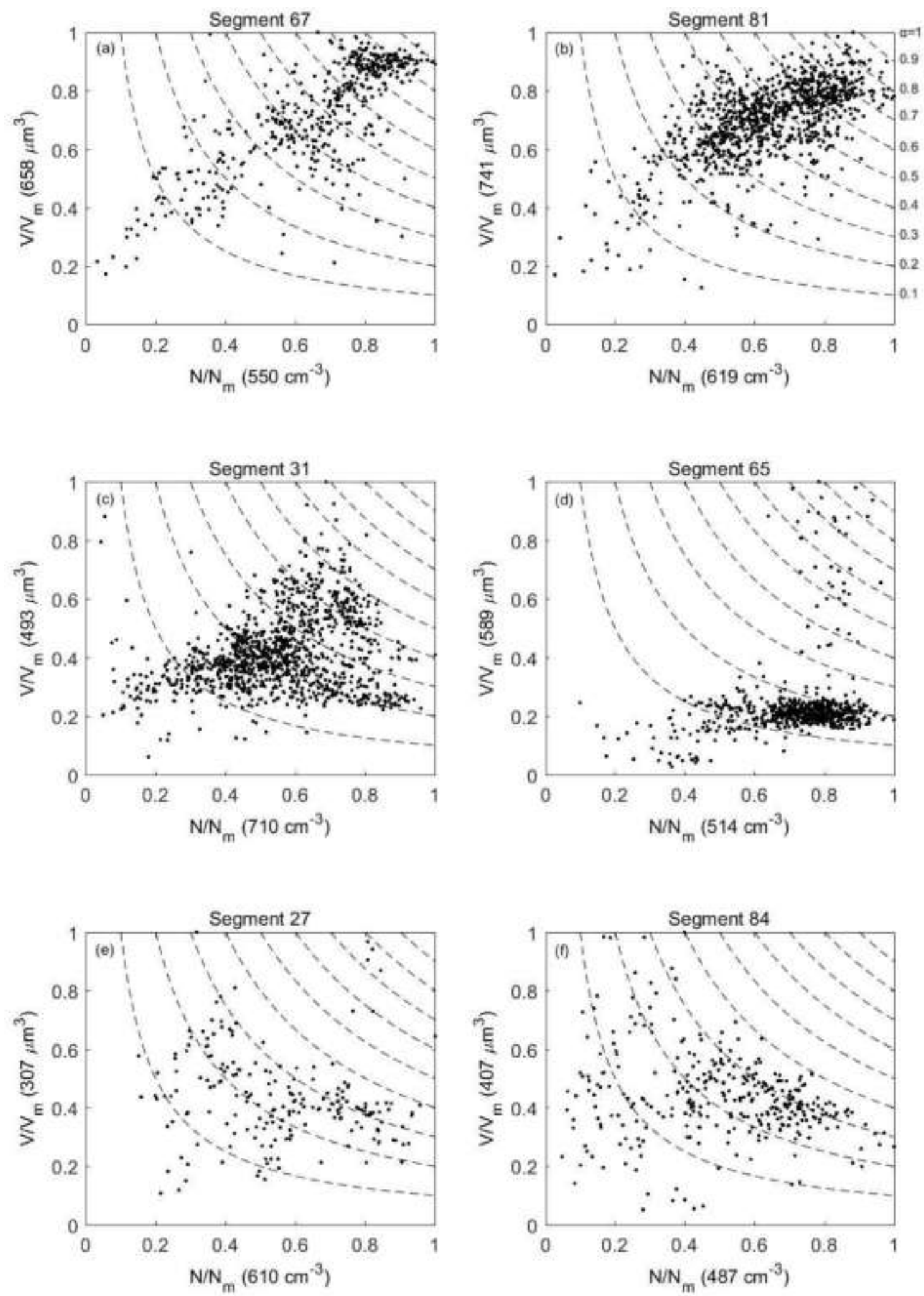

584 Figure 4. Mixing diagrams for some selected cloud segments. The maximum droplet number 585 concentration $\left(\mathrm{N}_{\mathrm{m}}\right)$ and volume $\left(\mathrm{V}_{\mathrm{m}}\right)$ for each segments, which are used as the proxy for 586 adiabatic ones, are shown in parentheses in $\mathrm{x}$ and $\mathrm{y}$ axis labels. The dashed lines indicate iso$587 \alpha$ lines. 


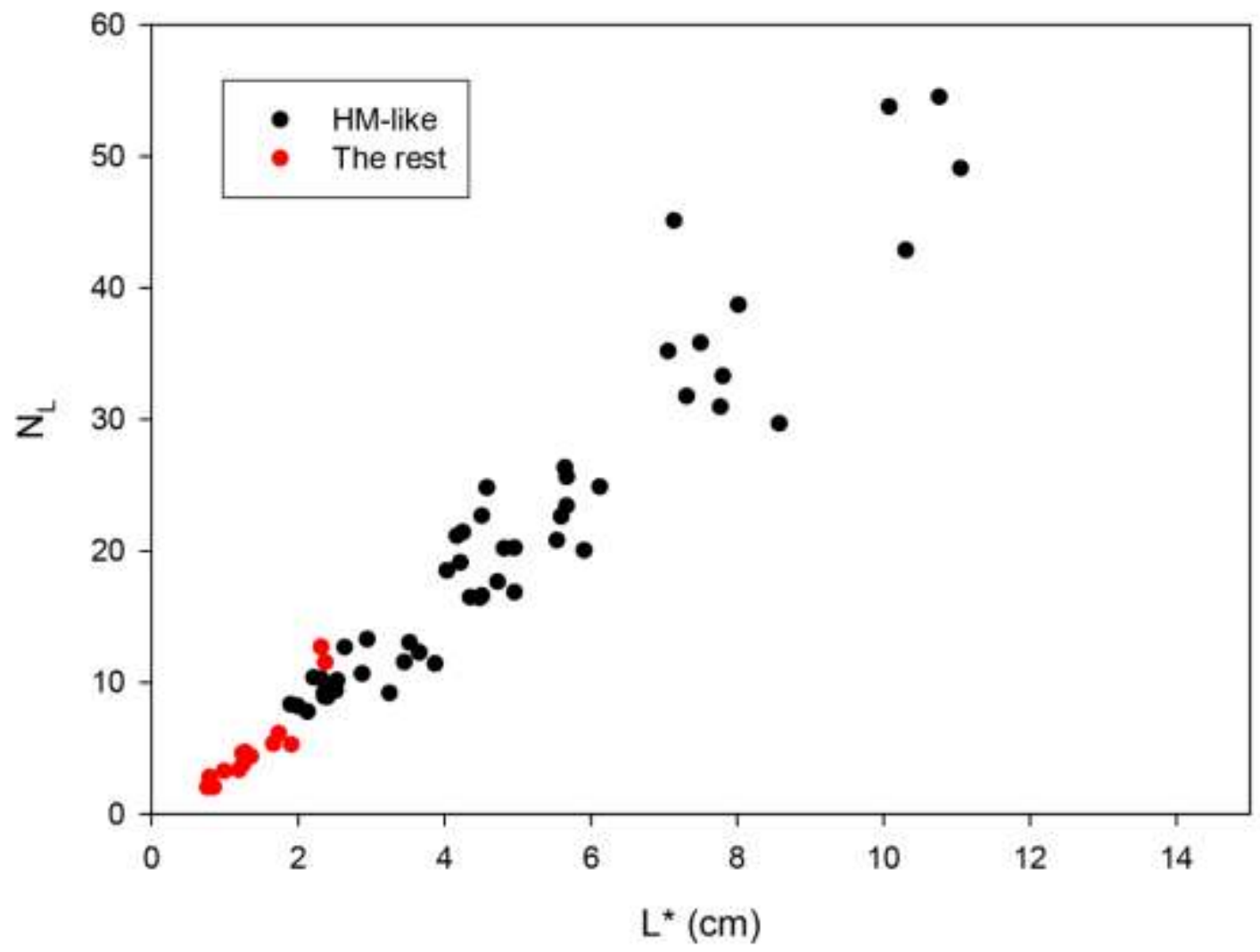

589 Figure 5. Scatterplot of the segment mean transition length $\left(\mathrm{L}^{*}\right)$ vs. the segment mean 590 transition scale number $\left(\mathrm{N}_{\mathrm{L}}\right)$. The segments classified as $\mathrm{HM}$ in Table 1 are marked with 591 black dots and the rest are marked with red dots.

592

593

594

595

596 

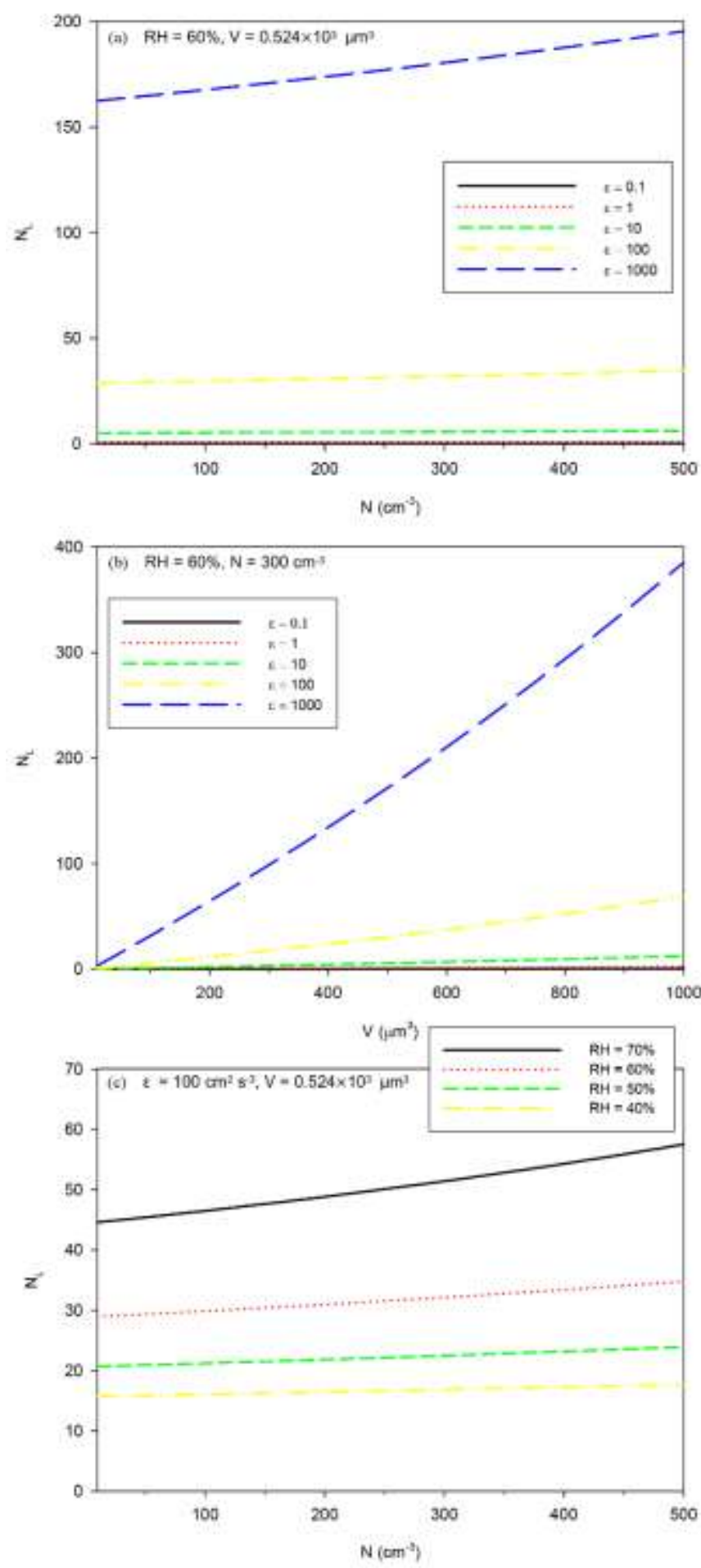

598 Figure 6. (a) Calculated transition scale number $\left(\mathrm{N}_{\mathrm{L}}\right)$ as a function of droplet number 599 concentration $(\mathrm{N})$ for several different turbulent dissipation rates $(\varepsilon)$ and (b) $\mathrm{N}_{\mathrm{L}}$ as a function 600 of mean volume of cloud droplets (V) for several different $\varepsilon$ and (c) $\mathrm{N}_{\mathrm{L}}$ as a function of $\mathrm{N}$ for 601 several different relative humidity (RH) of entrained air. In (a) and (b) RH is fixed at $60 \%$, 602 but $\mathrm{V}$ and $\mathrm{N}$ are assumed to be fixed as $0.524 \times 10^{3} \mu \mathrm{m}^{3}$ and $300 \mathrm{~cm}^{-3}$, respectively and in (c) 603 $\mathrm{V}$ and $\varepsilon$ are fixed at $0.524 \times 10^{3} \mu \mathrm{m}^{3}$ and $100 \mathrm{~cm}^{2} \mathrm{~s}^{-3}$. 

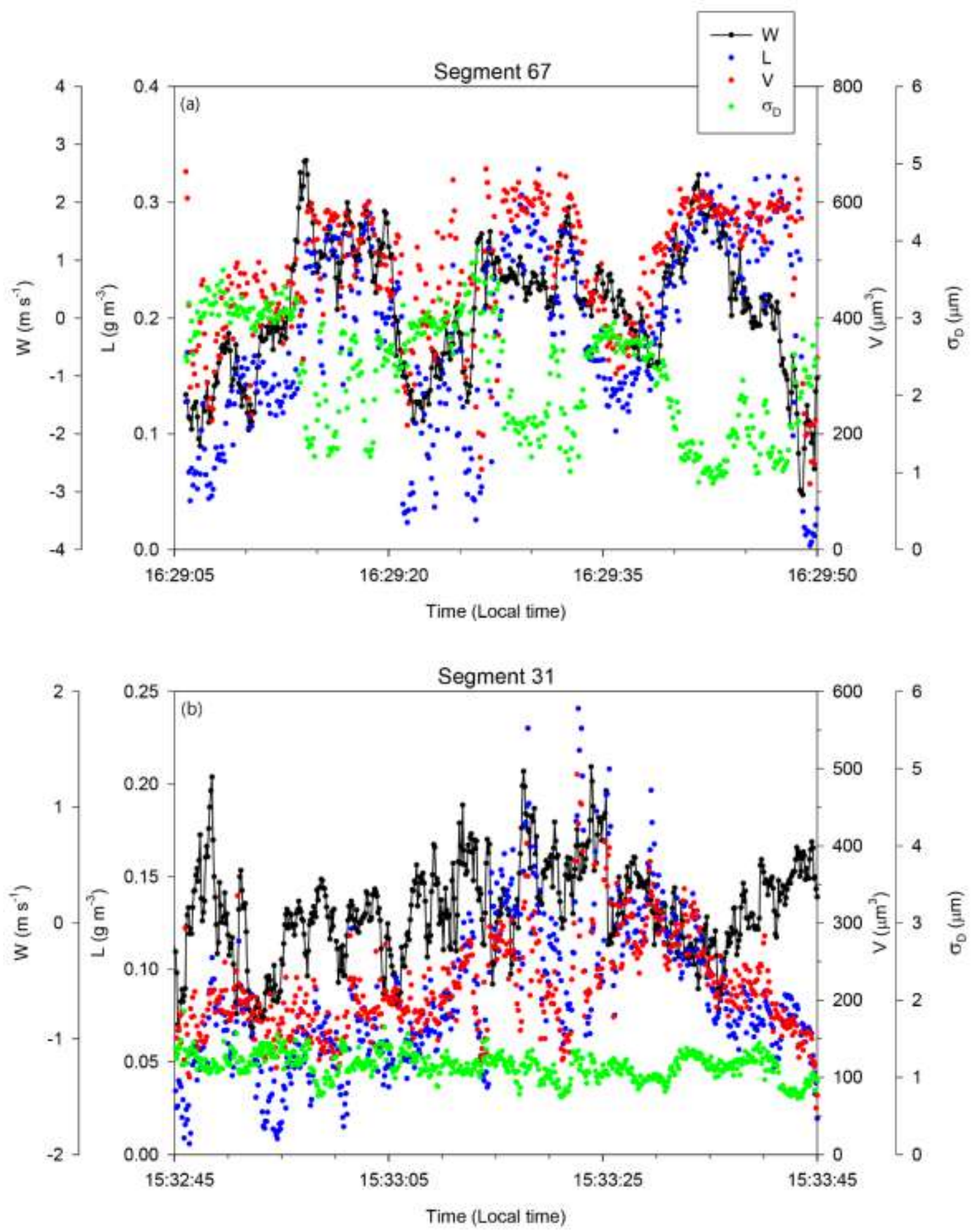

604

605 Figure 7. Time variation of cloud liquid water content (L), volume (V), standard deviation of 606 diameter $\left(\sigma_{\mathrm{D}}\right)$, and vertical velocity (W) for segments (a) 67 and (b) 31. 


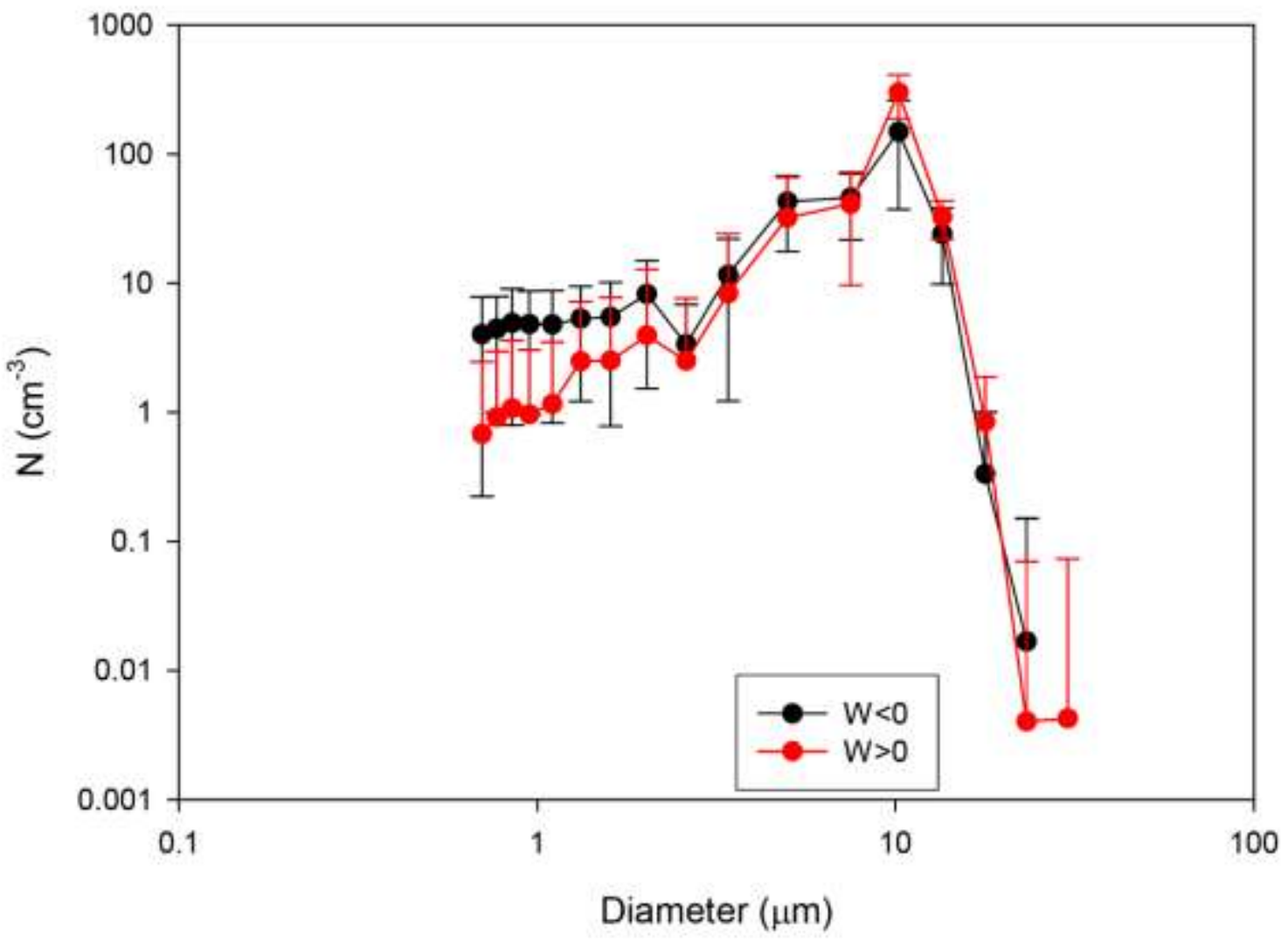

608 Figure 8. Mean droplet size distributions for the cloud parcels with vertical velocity (W) $>0$ 609 and $\mathrm{W}<0$ for segment 67.

610

611

612

613

614

615

616

617 

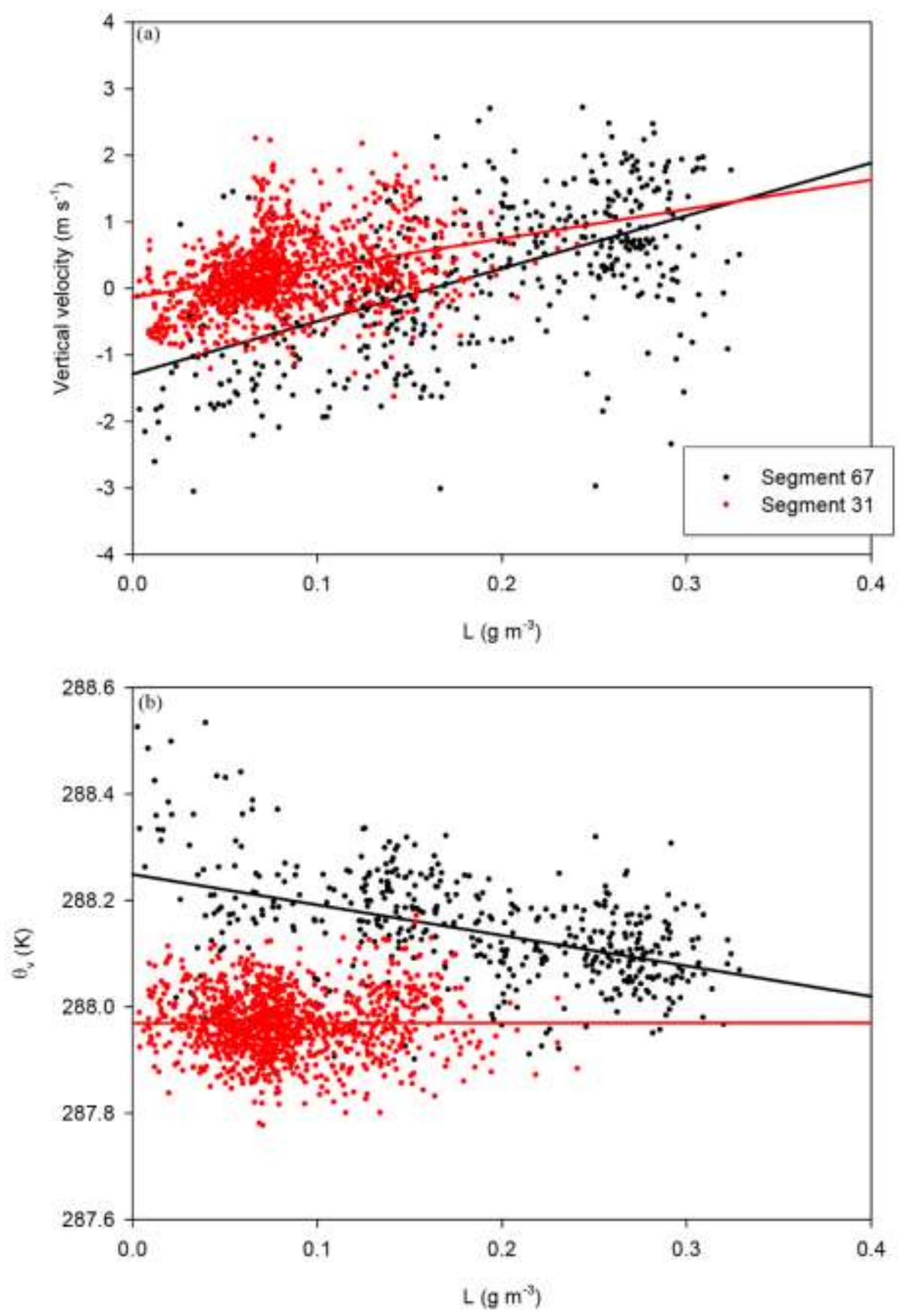

618

619 Figure 9. Relationships between liquid water content (L) and (a) vertical velocity, and (b) 620 virtual potential temperature $\left(\theta_{\mathrm{v}}\right)$ for segments 31 and 67 . Solid lines indicate regression lines. 